\title{
PNEUMONIA IN THE NEW-BORN
}

BY

AGNES R. MACGREGOR, M.D., F.R.C.P.E.

(From the Department of Child Life and Health, University of Edinburgh)

\section{PART I}

It is only within comparatively recent years that the prevalence of pneumonia among new-born infants has begun to be recognized. Since the work of HessThaysen (1914) first called attention to the great frequency of this disease, several workers (Browne, 1921, 1922 ; Johnson and Meyer, 1925 ; Cruickshank, 1930 ; Chase, 1935) have published the results of investigations of large series of cases, all proving that pneumonia is one of the principal causes of neonatal death. In spite of this it is probable that its great frequency has not yet been fully realized. This is largely due to the difficulty of clinical diagnosis, which is such that the vast majority of cases are not recognized unless a necropsy is performed, and even then, in many cases, only if the pathologist has experience of neonatal pathology and takes special care. As a result, the prevention of this disease receives in many quarters less attention than it deserves. This may be explained in part by a lack of clear knowledge of the causes and pathogenesis of neonatal pneumonia, for in spite of a considerable amount of pathological study much doubt and disagreement still exist as to the mode of infection, the relative importance of infection received before and after birth, the principal causative bacteria and on other fundamental questions. In particular, an extensive study of the literature showed that little attention has been paid to pneumonia developing after the first few days of life, and that knowledge of the bacteriology of all types of pneumonia in the neonatal period is surprisingly scanty.

\section{Present investigation}

The investigation of which an outline is now presented was undertaken in the hope that further study of the pathological features and bacteriology of pneumonia and allied pulmonary infections occurring before birth and during the first four weeks of postnatal life, and fuller understanding of the special features of the neonatal period that influence the onset and course of respiratory disease, might shed fresh light on this subject and indicate some of the lines along which the problem of prevention might profitably be approached.

The investigation consisted of a pathological examination of 541 consecutive necropsy cases of infants up to twenty-eight days old, among which 177 cases presented inflammatory changes in the lungs. Every case was subjected to 
microscopic examination, as it is recognized that the macroscopic diagnosis of neonatal pneumonia is often difficult and uncertain, especially when the lungs are unexpanded and unaerated and the pneumonia is accompanied by congestion, oedema and haemorrhage, as is often the case. Bacteriological examinations were made in 474 of the 541 necropsies, including 150 cases of pneumonia. The procedure included the examination of films and cultures from the lungs in every case, and of Gram-stained sections of lung in every case of pneumonia. Cultures were made from the heart blood in 250 cases, including 76 cases of pneumonia. The investigation included the examination of the clinical record of every case of pneumonia, as a knowledge of the facts of the maternal and obstetrical history is essential for a proper understanding of the pathological process and its possible causes, especially in the case of the youngest infants.

The 541 infants who made up the whole series examined post-mortem included 93 who were born dead and 448 who were born alive and survived not more than twenty-eight days. Among these there were 177 (32.7 per cent.) with inflammatory changes in the lungs, including 11 (11.8 per cent.) among the dead-born and 166 (37 per cent.) among the live-born. This number included three cases in which the inflammatory changes were confined to the bronchi.

Pneumonia was not in all cases the cause of death. A considerable number of the children had other lesions that might have proved fatal of themselves, and in some the pneumonia was of small extent and probably less important than associated conditions. There were, however, many cases in which the pneumonia was the sole and sufficient cause of death, and in all it must be regarded as at least an important contributory factor.

Age incidence.-The chart shows in graphic form the distribution of the pneumonia deaths throughout the twenty-eight days of the neonatal period. Pneumonia occurred in eleven dead-born infants. Eighty-nine (53 per cent.) of the live-born babies died in the first week of life ; 33 (20 per cent.) in the second

\section{CHART}

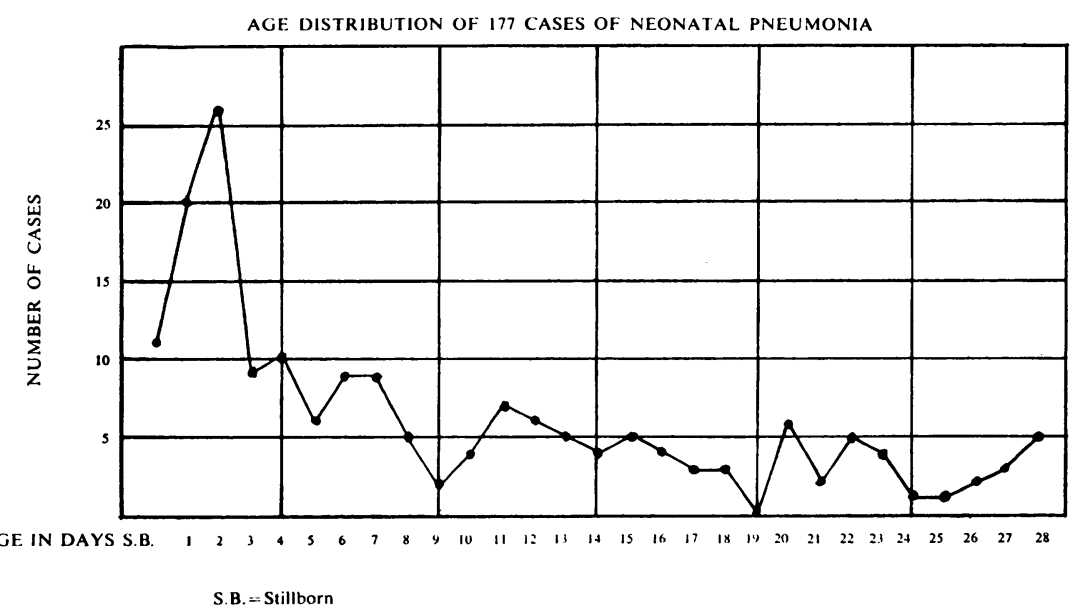


week ; 23 (13.8 per cent.) in the third week ; 21 (12.6 per cent.) in the fourth week. Forty-six pneumonia deaths $(27 \cdot 7$ per cent.) occurred in the first two days, the largest number on any one day being twenty-six on the second. The large excess of deaths in the first week is thus accounted for to a great extent by the heavy mortality in the first two days, some of which is attributable to associated conditions rather than to the pneumonia itself.

Maturity.-According to the commonly accepted standard, infants whose weight at birth exceeded $5 \frac{1}{2} \mathrm{lb}$. were regarded as mature, those below that weight as premature. Judged by this standard 100 of the 177 babies with pulmonary inflammation were mature, 77 were premature. It is to be noted that the proportion of premature babies among those who developed pneumonia (43.5 per cent.) is much higher than among all births (estimated at about 10 per cent. for hospital practice). This suggests that premature babies are specially susceptible to respiratory tract infections, an observation previously made by Browne (1922) and others.

Classification.-The pathological study of the 177 cases of pneumonia revealed that they could be divided according to their outstanding pathological characters into four distinct groups, thus :

1. Pneumonia associated with aspiration of contents of the amniotic sac or vagina : (a) in the dead-born (11 cases) ; (b) in the live-born (33 cases).

2. Pneumonia associated with other pulmonary conditions due to stress of birth or otherwise peculiar to the new-born : atelectasis, haemorrhage, (33 cases).

3. Bronchopneumonia and allied types ( 82 cases).

4. Septicaemia with secondary involvement of the lungs (18 cases).

As a general rule, to which only a few exceptions were found, cases belonging to groups 1 and 2 occurred in infants who were born dead or lived only three or four days after birth ; while those belonging to groups 3 and 4 occurred later, being frequent from the fourth day onward. It was in cases of groups 1 and 2 that the possibility of prenatal infection had to be considered ; those of groups 3 and 4 could, as a rule, be confidently attributed to infection received after birth. These differences in the age incidence of the various groups are shown in the table.

TABLE I

AGE IN RELATION TO PATHOLOGICAL TYPE OF PNEUMONIA

\begin{tabular}{|c|c|c|c|c|c|c|c|}
\hline \multirow{2}{*}{ TYPE OF PNEUMONIA } & \multicolumn{7}{|c|}{ AGE IN DAYS } \\
\hline & $\begin{array}{l}\text { STILL- } \\
\text { BORN }\end{array}$ & $0-3$ & $4-7$ & $8-14$ & $15-21$ & $22-28$ & TOTAL \\
\hline $\begin{array}{l}\text { Prenatal aspiration } \\
\text { Atelectasis } \quad \ldots \\
\text { Haemorrhage } \ldots \\
\text { Bronchopneumonia and } \\
\text { allied types } \ldots \\
\text { Haematogenous lesions }\end{array}$ & $\frac{11}{-}$ & $\begin{array}{r}31 \\
11 \\
7 \\
6 \\
-\end{array}$ & $\begin{array}{r}2 \\
6 \\
2 \\
\\
16 \\
8\end{array}$ & $\begin{array}{r}-2 \\
3\end{array}$ & $\begin{array}{c}\overline{1} \\
1\end{array}$ & E & $\begin{array}{l}44 \\
20 \\
13\end{array}$ \\
\hline
\end{tabular}


The remainder of this paper is occupied with a consideration of the types of neonatal pneumonia that are included in groups 1 and 2. Those belonging to groups 3 and 4 will be discussed in part II.

Pneumonia in the dead-born and in the earliest days of life.-In most cases of pneumonia in the dead-born and in infants who die in the earliest days of postnatal life, the pneumonia is accompanied by some condition of the lungs that must be regarded either as the direct cause or as an important predisposing factor. Chief among such conditions are : $(a)$ aspiration of contents of the amniotic sac or vagina ; $(b)$ persistent congenital atelectasis ; and (c) massive pulmonary haemorrhage. In the series investigated, all the cases of pneumonia with evidence of prenatal aspiration occurred in infants who died before the end of the fourth day and only three lived more than two days. The other conditions (atelectasis and haemorrhage) were occasionally associated with pneumonia in older infants, but the great majority of those affected died within a week of birth and most of them in the first three days.

Pneumonia associated with prenatal aspiration.-Material aspirated into the lungs of the foetus before or during the process of birth may consist either of contents of the amniotic sac or mucus from the vagina. In this series evidence of aspiration of amniotic sac contents was found much more often (41 cases) than evidence of aspiration of material from the vagina ( 3 cases).

Pneumonia with evidence of aspiration of contents of the amniotic sac.This group included all the dead-born infants with pneumonia (11) and 30 live-born, in all of whom there was clear evidence that an excessive quantity of liquor amnii had been drawn into the lungs. The presence of liquor amnii in the lungs is readily detected microscopically by solid material in the fluid (fig. 1). Of the various solid constituents the most often found are cornified

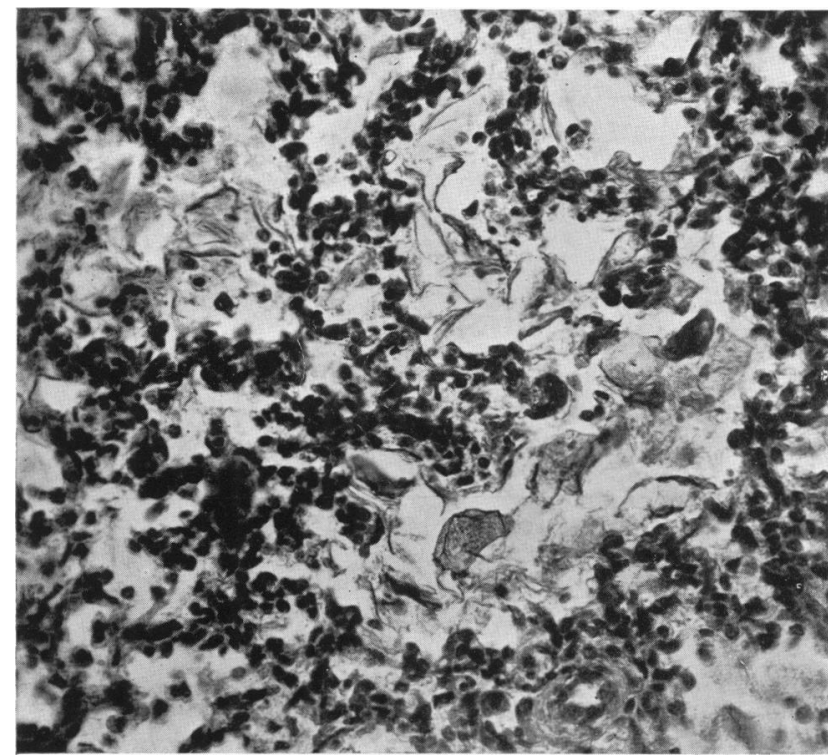

FIG. 1.-Lung of stillborn infant. Cornified cells and other debris from liquor amnii filling alveoli ; no pneumonia. H. and E. $\times 250$. 
squamous epithelial cells from the skin of the foetus. Lanugo hairs may also be seen. Vernix caseosa is not uncommonly found in the form of amorphous masses lying free in the alveoli or bronchi or adhering to their walls. In liveborn infants this material is sometimes found plastered against the walls of alveoli and bronchioles in the form of a continuous membrane. This is referred to again later. Sometimes meconium is found in the lungs. It may be obvious to the naked eye or recognized microscopically by the presence of bile-stained debris (fig. 2).

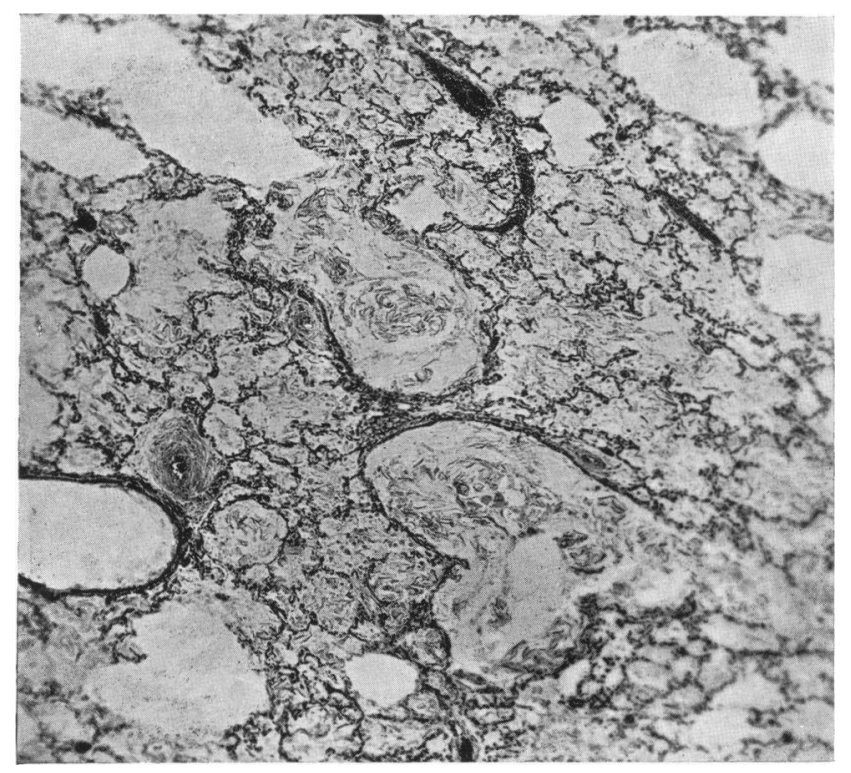

FIG. 2.-Lung of stillborn infant. Bronchioles and alveoli distended with meconium; no pneumonia. H. and E. $\times 60$.

The significance of finding amniotic sac contents in the lungs of infants has been disputed. Some observers (Ahlfeld, 1888 ; Leff, 1936 ; Snyder and Rosenfeld, 1937) have maintained that the presence of a considerable quantity of liquor amnii in the lungs of the new-born is not abnormal ; while others (Reifferscheid, 1911 ; Farber and Sweet, 1931 ; Helwig, 1933) regarded it as evidence of foetal asphyxia. In the writer's experience when any considerable amount of solid amniotic debris is found in the lungs, there is always other evidence of severe asphyxia, even in the dead-born, in whom the asphyxia could not be attributed to respiratory obstruction due to the presence of abnormal amniotic debris, as suggested by Snyder and Rosenfeld. It appears, then, that while small amounts may be disregarded, any large quantity of amniotic fluid in the lungs is an indication of foetal asphyxia. In all this group of cases, therefore, there was good reason to suppose that the child had been severely asphyxiated during birth.

The pneumonia was often slight in extent but sometimes widespread (fig. 3). Consolidation was not massive and was often difficult to detect at necropsy. $2 \mathrm{~A}$ 
It was accompanied in all cases by atelectasis and by varying degrees of congestion, oedema and haemorrhage. The distribution of the pneumonic exudate was either diffuse or patchy. The bronchi were often little affected ; they might show no inflammation and frequently remained unexpanded. The peribronchitis characteristic of true air-borne bronchopneumonia was not observed.

In eleven cases in live-born infants the condition described by Johnson and Meyer (1925) as 'hyaline membrane' and by Farber and Sweet (1931) and Farber and Wilson (1932) as 'vernix membrane' was observed (fig. 4 \& 5).

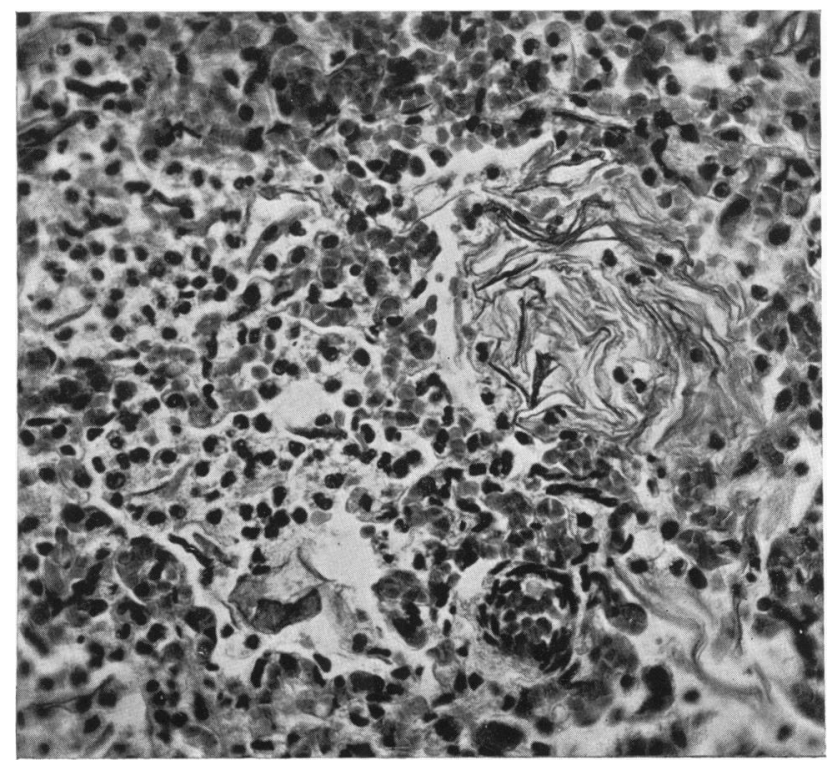

FIG. 3.-Lung of stillborn infant. A patch of pneumonia related to a deposit of amniotic debris. H. and E. $\times 250$.

This consists of homogeneous material, staining strongly with eosin and having a somewhat hyaline appearance, which lines the bronchioles, alveolar ducts, and alveoli with a thick, more or less continuous layer closely applied to the walls. Appropriate staining shows that it usually contains a large amount of fat. It is probable that in most cases, if not in all, it is composed of vernix caseosa, aspirated by the foetus along with liquor amnii. Vernix membrane was found only in live-born infants, though vernix masses were seen in the lungs of several of the dead-born. It is only when air enters the lungs that the material is plastered against the walls of the air-spaces in the form of a membrane. Lungs with vernix membrane always showed more than usually severe atelectasis, and in several cases the small parts that had been aerated showed acute vesicular and interstitial emphysema, with air bullae in the septa and under the pleura, a clear indication of serious obstruction to the passage of air. In keeping with this, these babies always showed at necropsy ample evidence of severe asphyxia, and their clinical records indicated that they had 


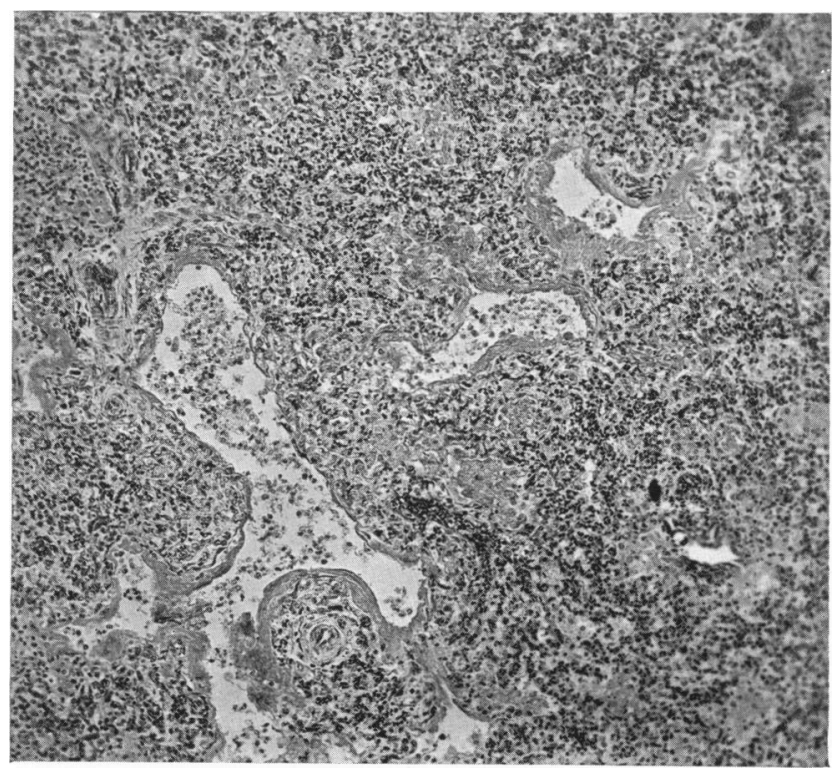

FIG. 4.- - Lung of infant aged two days, showing vernix membrane lining bronchioles, pneumonic exudate and extreme atelectasis. H. and E. $\times 80$.

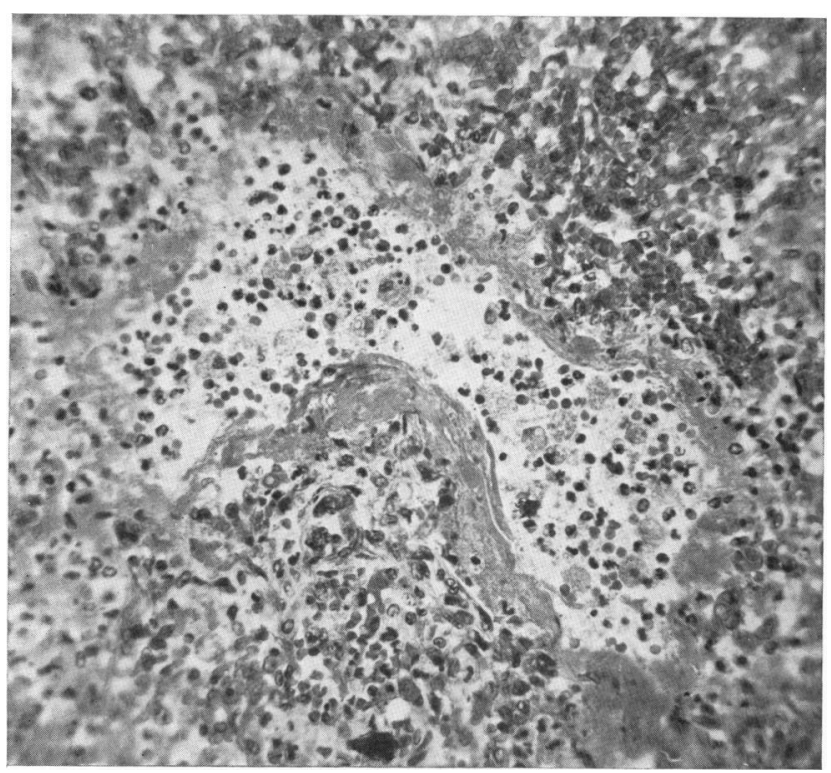

FIG. 5.-Lung of infant three days old. Bronchiole lined with vernix membrane and filled with inflammatory cells. H. and E. $\times 210$. 
been badly asphyxiated at birth and failed to breathe well. Vernix membrane often occurs without any inflammatory reaction. When pneumonia is present it has the same characters as in other cases with excessive aspiration of amniotic sac contents.

Many of the infants in whose lungs amniotic sac contents were found had, in addition to pneumonia, other lesions of a lethal character. Sixteen had sustained intracranial injury. Many had suffered severe asphyxia, which might well have proved fatal without pneumonia, and in several the blocking of the air-passages by liquor amnii or meconium was doubtless of greater importance than the pneumonia as a cause of death.

The obstetrical records revealed abnormalities of labour in fifteen cases. These included nine deliveries by forceps, four breech deliveries (two with forceps), two dry labours, two cases of Caesarian section. In one case the liquor amnii was noted to be foetid and the child developed a staphylococcal infection of the lungs with suppuration. In two cases the placenta was noted as being ' unhealthy' but there was no clear evidence of infection of the child from that source. One mother had an antepartum rigor and puerperal septicaemia, but there was no evidence of transplacental infection of her child.

Bacteriological examinations were made in the cases of ten dead-born and twenty-three live-born infants in this group. Among the dead-born six gave negative results, the cultures remaining sterile and examination of films of lung-juice and Gram-stained sections of lungs failing to reveal any bacteria ; three gave results that were considered to be inconclusive, as the organisms were probably contaminators ; and in one case, in which there was a long dry labour, b. coli was considered to be responsible for the pneumonia. Among the live-born three cases gave negative and nine cases inconclusive results, while eleven gave positive results : in one a pure infection with $b$. influenzae, in one a pure infection with staphylococcus aureus; in the rest, viridans type and indifferent streptococci and coliform bacilli occurred alone or together.

Pneumonia with evidence of aspiration of contents of the vagina.-In three children, who lived twelve, twenty and twenty-nine hours, the bronchi were filled with masses of mucus heavily infected with bacteria, and a severe inflammation had arisen, beginning in the bronchi and spreading to produce extensive consolidation. The lungs contained no recognizable amniotic debris. It seemed probable that the heavily infected material in the bronchi had been aspirated from the genital tract during birth. The bacteria were streptococcus viridans in one case, $b$. coli in one and non-haemolytic streptococci together with b. coli in the third. One case was a breech delivery, one a forceps delivery with face presentation, one a spontaneous delivery with vertex presentation, but the child was asphyxiated at birth. In all cases, therefore, premature respiratory efforts by the foetus were probable and might have caused aspiration of bacteria-laden mucus from the vagina. 
Pneumonia associated with other pulmonary conditions caused by stress of birth or otherwise peculiar to the newborn

Persistent congenital atelectasis.-Lungs in which aspirated amniotic sac contents were found always showed more or less severe congestion and atelectasis and a water-logged condition due to the aspirated fluid. In the cases now to be considered the state of the lungs was similar and the pneumonia assumed the same characters, but no clear evidence of excessive aspiration was found. There were twenty such cases and they all had certain features in common. The lungs were poorly expanded, congested and oedematous. The pneumonia was, in most cases, not very extensive. Its pathological characters were the same as in the cases with aspirated liquor amnii. Almost all the children had exhibited conditions that might explain the persistence of atelectasis : most were severely asphyxiated or feeble at birth ; eight had intracranial haemorrhage ; all who presented no other reason for persistent atelectasis were premature and puny. The obstetrical records revealed one case of Caesarian section; two forceps deliveries, one by the breech; two dry labours; one case of hydramnios; and five cases of toxaemia of pregnancy.

Massive pulmonary haemorrhage.-In all types of neonatal pneumonia some amount of haemorrhage is common, depending either upon the intensity of the inflammatory reaction or upon accompanying asphyxial congestion. But there was a group of cases in which haemorrhage appeared to be the primary event, the inflammatory reaction developing secondarily in tissue devitalized by haemorrhage. Massive pulmonary haemorrhage is not uncommon in the new-born and may be a cause of death, usually in the first few days of life. It may be so severe that almost the whole of both lungs is consolidated, or it may affect localized patches of varying extent (fig. 6). The cause is obscure. Browne $(1921,1922)$ called it 'acute haemorrhagic pneumonia ' and believed it to be the first stage of an intense inflammatory reaction. Ylppö (1919) ascribed it to bacterial action. Cruickshank (1930) attributed it as a rule to asphyxia, but noted that many babies in whom it occurred were born of toxaemic mothers. It was seen many times during the present investigation, sometimes associated with infective conditions but more often without any evidence of infection. Usually it was not accompanied by an inflammatory reaction in the lungs. The haemorrhage, however, causes devitalization of the lung tissue by arresting or impairing the circulation. Bacterial infection may then gain access to the devitalized part and set up an inflammatory reaction. This, in the present series, was always slight and confined to small areas of necrotic tissue among much more widespread haemorrhage.

There were thirteen examples of this lesion. Nine of the babies died in the first week, seven in the first three days. Seven were premature. Seven had intracranial haemorrhage, usually subarachnoid or intraventricular. In four of the younger babies there was severe birth asphyxia. One child had multiple haemorrhages. In only one was there evidence of any infective condition apart from the lungs (peritonitis). Two mothers had toxaemia of pregnancy. Bacteriological examinations were made in nine cases. The results were 
negative in two and inconclusive in four; three yielded non-haemolytic streptococci, accompanied by b. coli in two.

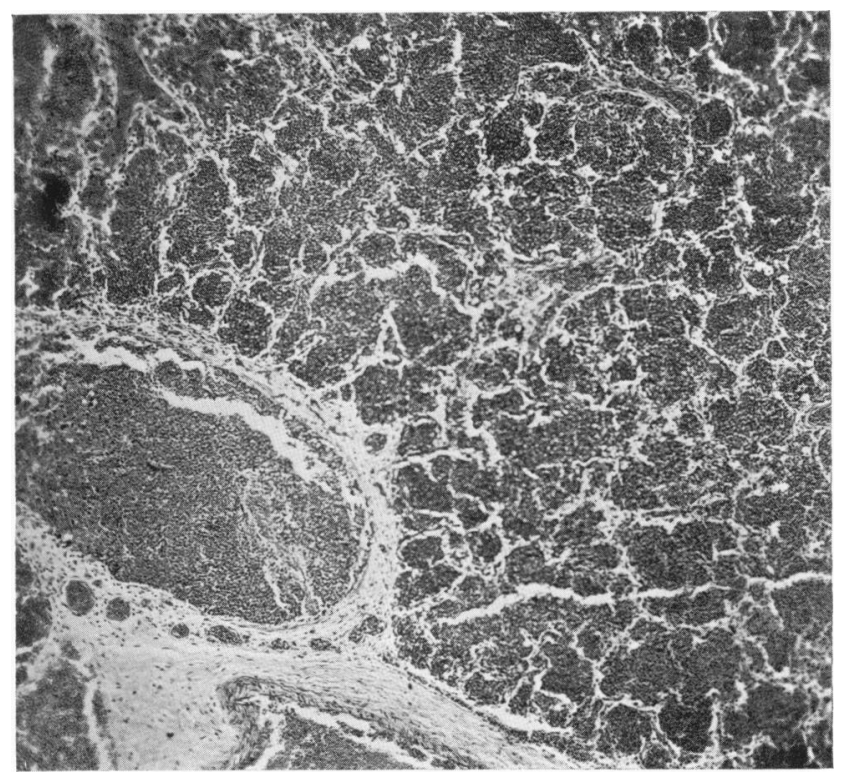

FIG. 6.-Lung of infant three days old. Massive pulmonary haemorrhage filling bronchus and alveoli ; no pneumonia. H. and E. $\times 70$.

\section{Discussion}

In this series of cases pneumonia in dead-born infants and in those who survived birth not more than twelve hours was invariably associated with aspiration of an excessive quantity of liquor amnii, with or without meconium, into the lungs; and in a large proportion of the live-born infants who died within three or four days of birth the same condition was present. This means that in all cases in which the pneumonia certainly developed before birth, and in most cases in which it may have done so, excessive aspiration of amniotic sac contents had occurred, and it suggests that the inflammatory reaction in the lungs depended on the presence of aspirated material.

The fact that bacteriological investigation of cases of this type often gave negative or inconclusive results suggests that the presence of bacteria may not be the only cause of the inflammatory reaction, and that the irritant may be chemical or mechanical and present in the liquor amnii itself. It is not implied that liquor amnii is always capable of producing an irritant effect ; that is quite evidently not the case. But the evidence does suggest that some cases of pneumonia may be due to irritating constituents of the liquor amnii. Various workers (Johnson and Meyer, 1925 ; Helwig, 1933 ; Warwick, 1934) have suggested that liquor amnii, or some of its constituents, may sometimes act as an irritant especially when there is meconium in it. In this series the only case in a dead-born infant in which satisfactory evidence of bacterial 
infection was obtained was one with a history of a long dry labour terminated by forceps delivery, in which infection of the contents of the uterus was probable. It would be unjustifiable to draw dogmatic conclusions from the evidence derived from this investigation, but some of the cases are difficult to explain except on the assumption that the inflammatory reaction in the lungs was caused by a non-bacterial irritant in the aspirated material.

In the case of live-born infants it may be impossible to determine if bacterial infection, when proved to be present, took place before or after birth. In certain cases there was no sufficient evidence of any bacterial infection, and in the case of infants who lived a day or two bacterial infection, when found, might have been received after birth.

Pneumonia due to a non-bacterial irritant is unlikely to be severe or progressive. It is noteworthy that in all cases with advanced consolidation bacteria were proved to be present. It is of interest also that in those cases in which it seemed certain that the pneumonia was due to prenatal bacterial infection there was usually a history of some condition that rendered such an event probable, e.g. a long dry labour or gross infection of the liquor amnii ; and such cases presented more definite evidence of septic aspiration than the rest.

The conclusion arrived at from the study of all the cases, in dead-born and live-born, in which there was evidence of prenatal aspiration, was that bacterial infection before birth is not common, but when it does occur it has disastrous consequences for the child ; that a certain number of cases of pneumonia with prenatal aspiration may be caused by a non-bacterial irritant in the aspirated material ; and that the conditions produced in the lungs by aspiration, and by the accompanying effects of asphyxia, are favourable to bacterial invasion after birth.

The cases of pneumonia associated with atelectasis had certain features in which they closely resembled those with prenatal aspiration, although direct evidence of the presence of amniotic fluid in the lungs was lacking. In both groups the lungs were deficiently expanded, poorly ventilated, congested and water-logged. In both the pneumonia had similar characters. As regards the bacteriological findings also the two groups were similar: the bacteria most often associated with both types were low-grade organisms, such as the non-haemolytic streptococci and coliform bacilli, rather than the more commonly recognized virulent pathogens, such as streptococcus haemolyticus, pneumococcus and $b$. influenzae.

None of the cases with atelectasis presented any direct evidence of prenatal infection, although in some of them there were circumstances that rendered such an event not improbable. As all the babies lived more than twenty-four hours, there could be no certainty that infection had been received before birth, and in the case of those who lived several days postnatal infection was more probable. It would appear therefore that the special characters of the pneumonia in these two groups are determined by the state of the lungs in which the inflammatory reaction develops, especially the presence of oedema and atelectasis. And this state, whether occasioned by prenatal aspiration or due to another cause, offers a peculiarly favourable nidus in the lungs for the settle- 
ment and growth of bacteria, no matter whether these are introduced by aspiration before delivery or by inhalation thereafter. It follows that if the occurrence of these conditions could be avoided many of the cases of pneumonia that fall into these two groups could be prevented.

It has already been explained that the available evidence justifies the opinion that excessive aspiration of liquor amnii or material from the vagina is caused by foetal asphyxia, which occasions premature and excessively vigorous respiratory efforts on the part of the unborn child. All cases of pneumonia with prenatal aspiration may therefore be attributed directly or indirectly to foetal asphyxia. Persistent atelectasis without prenatal aspiration may have various causes, but of these probably the most important is severe asphyxia, with resultant depression of the respiratory centre.

Henderson (1931) showed that beyond a certain point asphyxia produces a depressant or even a paralyzing effect on the respiratory centre. Many infants suffer during birth from asphyxia severe enough to produce a depressant effect and difficulty is experienced in establishing respiration. Moreover, the respiratory centre may continue to be in a state of subnormal activity for some time, so that respiration is feeble and full expansion and aeration of the lungs do not take place. Under these conditions there develops in the lungs a state of congestion, oedema and under-ventilation, which is peculiarly favourable to the development of pneumonia. Cruickshank (1930) laid great emphasis upon the importance of atelectasis as a factor predisposing to pneumonia in the new-born. Henderson went so far as to assert that if effective steps were taken to ensure complete expansion of the lungs as soon as possible after birth, neonatal pneumonia would be largely eliminated.

Facts observed in the course of this investigation left no room for doubt that atelectasis and the congestion and oedema associated with it were of the utmost importance in predisposing to the onset of pneumonia and determining its spread. The results of this study thus fully support the view advanced by Cruickshank and Henderson that, if respiratory depression resulting from asphyxia could be prevented or effectively treated, many infant lives could be saved that at present are lost from persistent atelectasis and from pneumonia developing as a sequel to it.

\section{Conclusions}

From this study of the types of pneumonia most prevalent in the dead-born and in the early days of postnatal life (those associated with prenatal aspiration and those with atelectasis, which together accounted for nearly all the cases that were fatal in the first three days) one fact that emerges unmistakably is the outstanding importance of asphyxia of the child as a causative factor. It is asphyxia that causes excessive aspiration of amniotic sac contents or vaginal secretion and therefore underlies nearly all cases of true congenital pneumonia. It is asphyxia that produces the pulmonary congestion and oedema, and sometimes the haemorrhage, that afford so favourable a medium for the proliferation of bacteria introduced either before or after delivery. It is asphyxia that causes 
the depression of the respiratory centre to which persistent atelectasis with all its attendant dangers is most often due.

It may be doubted if it is sufficiently clearly and universally recognized what risks to the child are incurred when asphyxia during birth is permitted to develop beyond the moderate degree that is harmless and inevitable ; and if the question of prompt and effective treatment designed to prevent its persistent or delayed effects has been given the full attention it deserves in view of its extreme importance to the preservation of infant life.

\section{Summary}

The results of a pathological and bacteriological investigation of 177 cases of pneumonia in infants who were born dead or died within twentyeight days of birth are presented. Pneumonia occurred in 32.7 per cent. of 541 necropsies on such infants. A classification of types of neonatal pneumonia according to the chief pathological characters is given. The pathological characters and pathogenesis of the types of pneumonia that occur in the deadborn and in those who die in the first few days of life are discussed. The importance of asphyxia as a factor in the production of these types of pneumonia is emphasized.

\section{REFERENCES}

Ahlfeld, J. F. (1888). Verh. Dtsch. Ges. Gynäk., 2203.

Browne, F. J. (1921). Edinb. med. J., 27, 153.

- (1922). Brit. med. J., 1, 469.

(1922). Ibid., 2, 590.

Chase, W. H. (1935). Canad. med. Ass. J., 32, 2.

Cruickshank, J. N. (1930). Medical Research Council Special Reports, No. 145.

Farber, S., and Sweet, L. K. (1931). Amer. J. Dis. Child., 42, 1372.

Farber, S., and Wilson, J. L. (1932). Arch. Pathol., 14, 437.

Helwig, F. C. (1933). Amer. J. Obstet. Gynec., 26, 849.

Henderson, Y. (1931). J. Amer. med. Ass., 96, 495.

Hess-Thaysen, T. E. (1914). Jhrb. Kinderheilk., 79, 140.

Johnson, W. C., and Meyer, J. R. (1925). Amer. J. Obstet. Gynec., 9, 151.

Leff, M. (1936). Ibid., 32, 286.

Reifferscheid, K. (1911). Dtsch. med. Wschr., 19, 877.

Snyder, F. F., and Rosenfeld, M. (1937). J. Amer. med. Ass., 108, 1946.

Warwick, M. (1934). Amer. J. med. Sci., 187, 253.

Ylppö, A. (1919). Z. Kinderheilk., 20, 371. 


\section{PART II}

When pneumonia develops more than two or three days after birth, it may be attributed in most instances to postnatal infection. Such cases fall into two distinct groups : postnatal respiratory tract infections, which, in the classification given in the previous paper (part I) formed group 3 under the title 'bronchopneumonia and allied types'; and septicaemic cases with lung lesions.

1. Postnatal respiratory tract infections.-Among the eighty-two cases that formed this group the majority had the characters of typical bronchopneumonia (fifty-five cases), whilst some had special features associated with special types of bacterial infection (sixteen cases). There was also a small

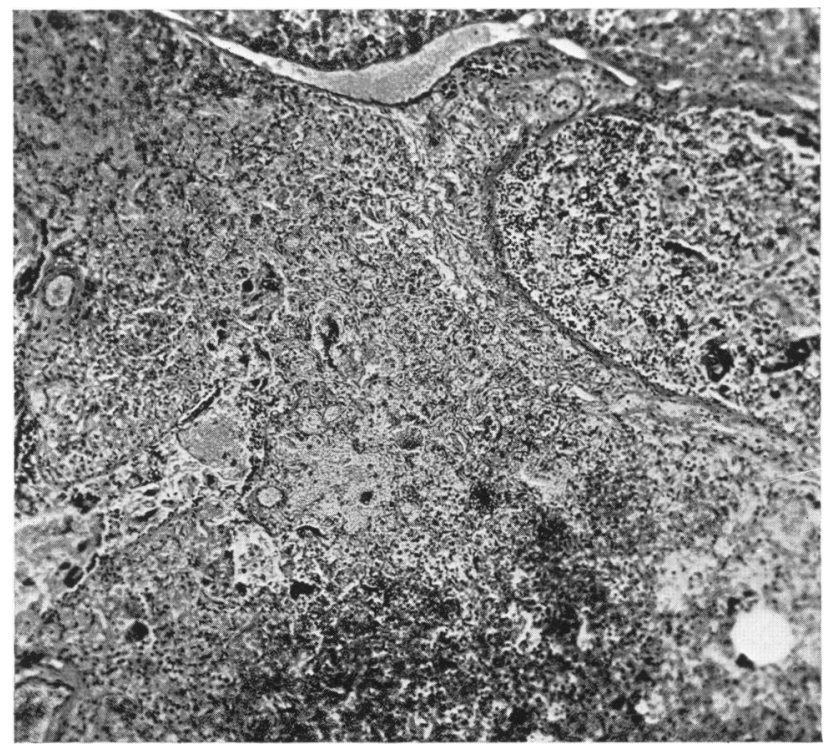

Fig. 1.-Lung of infant ten days old. Pneumonia due to aspiration of stomach contents : foreign matter in bronchus; haemorrhage, necrosis and consolidation of lung substance. H. and E. $\times 70$.

group (eight cases) in which pneumonia had resulted from septic aspiration after birth and isolated examples of bronchitis without pneumonia (one case) and terminal hypostatic pneumonia (two cases) to which no further reference need be made.

SEPTIC ASPIRATION AFTER BIRTH.-In most of these eight cases the foreign material found in the lungs was milk curd or gastric contents. In one case, in which the child developed acute intestinal obstruction from volvulus, the lungs and air passages were full of meconium which had been vomited. There was a history of vomiting in three other cases. The lungs lesion in all these cases was extensive and of a grave type, with haemorrhage and suppuration (fig. 1). Bacteriological examinations revealed mixed infections, always heavy. 
The liability of new-born infants to this type of pneumonia is probably to be explained by their tendency to regurgitate stomach contents and the risk that these may enter the trachea if the child is lying in an unsuitable position.

TYPICAL BRONCHOPNEUMONIA, of which there were fifty-five cases, was the largest pathological group. It is necessary at this point to define what is meant by 'typical bronchopneumonia.' Most of the types of pneumonia considered hitherto in these studies (e.g. that caused by aspiration and that associated with atelectasis) are forms of bronchopneumonia, but in some respects atypical because of the mode of infection or the conditions obtaining in the affected lungs. The cases now to be considered were different in certain particulars and bore a closer resemblance to bronchopneumonia as it is commonly seen in older infants and children as a result of air-borne infection.

In a study of pneumonia in childhood McNeil, Macgregor and Alexander (1929) gave a description of the pathological changes in the lungs in bronchopneumonia, and emphasized certain features of the process which they regarded as distinctive and essential. The chief among these is bronchitis, which is the initial lesion. This is an intense inflammation involving the whole bronchial wall and its lymphatic plexus, and produces, in addition to catarrh, an interstitial inflammation, indicated by swelling and inflammatory cell infiltration, which varies in severity in different cases, but is always present in some degree. The spread of the inflammation to the alveoli is in part a direct spread along the lumen of the bronchus to its terminal expansions and in part peribronchial, through the thickness of the wall to immediately adjacent alveoli which are not in communication with the lumen. This interstitial inflammation with lymphangitis was regarded by these workers as 'a constant feature of all forms of true bronchopneumonia and . . . of the very essence of the pathological process.' Holt and McIntosh (1933) also considered interstitial inflammation to be an essential feature of true bronchopneumonia, and Chase (1935) regarded it as an important point of distinction between cases in which pneumonia in the new-born followed extra-uterine upper respiratory tract infection (i.e. true or typical bronchopneumonia), and those in which it was caused by direct aspiration.

In the selection of cases for inclusion in the group of typical bronchopneumonia the features that were regarded as essential were : (1) bronchitis severe enough to produce not merely superficial catarrh but some amount of interstitial inflammation of the bronchial walls ; (2) a strictly bronchial and peribronchial distribution of the pneumonia ; and (3) absence of evidence of aspiration of foreign material into the lungs (fig. 2).

The ages of children in this group ranged from thirty hours to twenty-eight days. Only four were under four days old, after which age cases were frequent throughout the rest of the month. Typical bronchopneumonia was responsible for only a very few cases in the first three days of life, but from the fourth day onward it was much the commonest type.

In most cases consolidation was moderate or extensive and usually affected both lungs. Some confluence of pneumonic patches was usual, sometimes involving a whole lobe or more in one or both lungs, and being as a rule of greatest extent in the lower lobes. Microscopic examination showed that the exudate was cellular, rich in polymorphs and often accompanied by a large 
amount of oedema, haemorrhage and collapse of unfilled alveoli. Bronchi formed the centres of consolidated patches and showed the inflammatory changes already indicated. Suppuration occurred in three cases, originating in bronchi. Pleurisy was found in only three cases.

In this group twenty-five of the babies were premature. Only a small minority had other pathological conditions unconnected with the pneumonia. A considerable number, however, had stomatitis. The proportion of abnormal labours was not high and obstetrical difficulties and complications appeared to have no bearing on the development of pneumonia in the children.

Bacteriological examinations were carried out in forty-seven cases, with

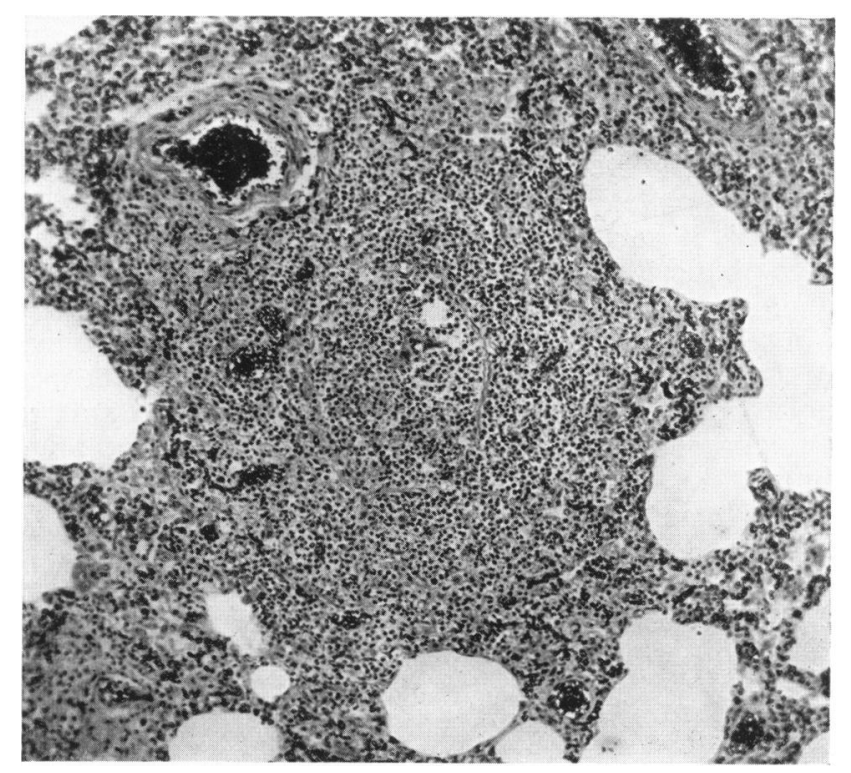

FIG. 2.-Lung of infant twenty-five days old. Typical bronchopneumonia : central bronchus filled with exudate and obscured by inflammatory infiltration ; consolidation of related alveoli. $\mathrm{H}$. and E. $\times 80$.

nine inconclusive and thirty-eight positive results. Pneumococci were isolated from six cases, always accompanied by other organisms, most often b. influenzae. Streptococcus haemolyticus occurred in five cases, alone in three, streptococcus viridans in two ; indifferent streptococci in nine, usually in association with other organisms; b. influenzae in eight, alone once; and bacilli of the b. coli group in sixteen, alone in nine.

The cases of this group may be regarded as representing the common form of pneumonia in the new-born that results from postnatal air-borne infection. That this was the mode of origin is suggested by their resemblance to cases known to be so caused in older infants and by the age incidence of the type in the present series. It is true that in the youngest infants in the group a birth infection was possible, though without evidence either from the pathological study or from the clinical history ; but there was no case which might not have 
developed entirely after birth. No well-developed case was seen before the fourth day. For reasons that will be given later, the writer is not of opinion that the frequency of infections with coliform bacilli means a corresponding frequency of infection acquired before delivery.

STAPHYlococCal PNEUMONia.-Pneumonia due to infection with staphylococci (other than haematogenous infection) is a type of bronchopneumonia, but, as seen in the course of this investigation, it had features so constant and distinctive that it is convenient to place such cases in a group by themselves. In the present series there were ten cases, excluding one referred to in the previous paper in which grossly infected liquor amnii was the source of infection.

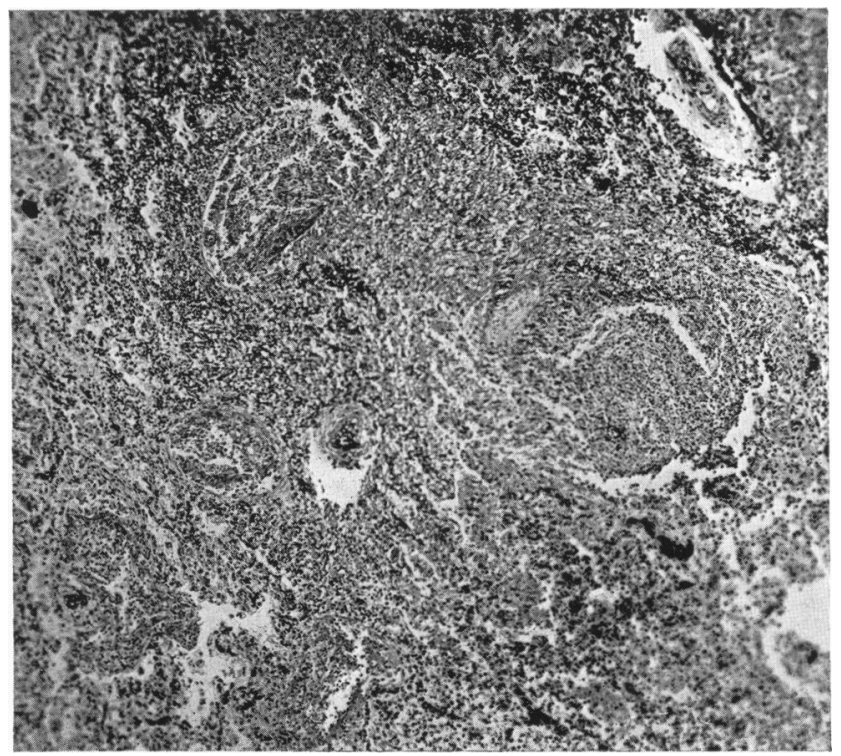

FIG. 3.-Lung of infant eighteen days old. Staphylococcal pneumonia : suppuration destroying bronchi and spreading widely. $\mathrm{H}$. and $\mathrm{E}$. $\times 50$.

The ages of the infants ranged from four to twenty-three days, five being in the first week.

All these cases presented similar pathological characters and closely resembled those described in a previous paper (Macgregor, 1936). In every case pleurisy was present, with an effusion of turbid, blood-stained fluid and purulent or fibrinous exudate. Pneumonia occurred in one or more rather sharply defined patches of massive consolidation, always intensely haemorrhagic, and showing suppuration in the form of ramifying pus-filled cavities (fig. 3). Other parts of the lungs were usually free from pneumonia and there was no generalized bronchitis. Only in one case, in which there was a mixed infection, was there pneumonic consolidation in parts that did not present the appearance described. Microscopic examination showed that the consolidation was due to a combination of massive haemorrhage and inflammatory exudation with a strong tendency to rapid suppuration, which began in the bronchi and spread 
into adjacent alveoli, so that abscess cavities were formed and extended in ramifying fashion along the bronchi and along infected lymph vessels. In no case was any evidence found of aspiration of foreign material into the lungs. There was nothing relevant in the maternal histories. Seven of the babies were premature. In no case was there any associated condition likely to have been the source of a generalized blood infection, and no case presented any metastatic lesions. One baby was believed to have been infected from another who shared an incubator and who had a staphylococcal stomatitis. In all cases staphylococcus aureus was isolated from the lungs. In nine the staphylococcal infection appeared to be pure ; in one b. coli communis was isolated from a consolidated area that did not show the appearance of staphylococcal pneumonia, and staphylococcus aureus from the characteristically affected part. This type of pneumonia is due to an infection that enters the lungs by the bronchi. Some of its features, particularly its localization and the heaviness of the bacterial infection, suggest that it may be caused by aspiration of grossly infected foreign matter. Johnson and Meyer (1925) thought that staphylococcal infection of the lungs might be caused by aspiration of milk. In the present series there was no evidence obtainable either from the history or from the pathological examination, to suggest any such occurrence or aspiration of any other foreign matter.

PneumococCal alveolar PNeumonia.-Holt and McIntosh (1933) described a type of pneumonia in young infants in which the patches bear no relation to bronchi and interstitial inflammation is absent, and which they distinguished from bronchopneumonia under the name of 'lobular pneumonia.' In the present series there was a small group of six cases to which this description could be applied. The children's ages ranged from three to twenty-seven days, all but the youngest being over ten days old. The pneumonia occurred in wellexpanded lungs. The consolidation was patchy, the patches being of variable size and often large. Within the patch consolidation was complete and uniform, so that the affected part stood out above the level of adjacent aerated substance, a feature seldom noted in bronchopneumonia owing to associated secondary collapse. The patches were sharply defined, often having a clear, straight margin. They were uniform in colour and consistence, and on section presented a drier surface than in typical bronchopneumonia, the appearance, but for the patchy distribution, being reminiscent of lobar pneumonia at the stage of red hepatization. Pleurisy was not present in any case. Microscopically the pneumonic areas showed complete and uniform consolidation, all the alveoli being fully expanded and filled with cellular exudate. The bronchi contained exudate similar to that in the alveoli and shared in the general congestion, but otherwise showed little inflammatory change (fig. 4). The sharply defined margins of the consolidated areas were due to their being bounded by interlobular septa, and beyond the boundary of the patch the lung substance was fully aerated and did not show either bronchitis or outlying patches of consolidation related to bronchi. There was no true bronchitis or interstitial inflammation. The consolidation had not a strict bronchial or peribronchial distribution, but occurred in lobules or groups of lobules. These features 
of the pathological process separated them from the group of typical bronchopneumonia.

Bacteriological investigation resulted in the isolation from each case of a pneumococcus in pure culture : Type I in two cases ; Type II in three cases ; Type III in one case. The particular type of pathological process exemplified by these cases is thus apparently characteristic of pneumococcal pneumonia in the new-born. The term 'alveolar pneumonia' is suggested as a suitable designation for this type. This name was applied by McNeil, Macgregor and Alexander (1929) to pneumonia of the lobar or croupous type in children, in whom it is often not of lobar extent. It indicates that the inflammation

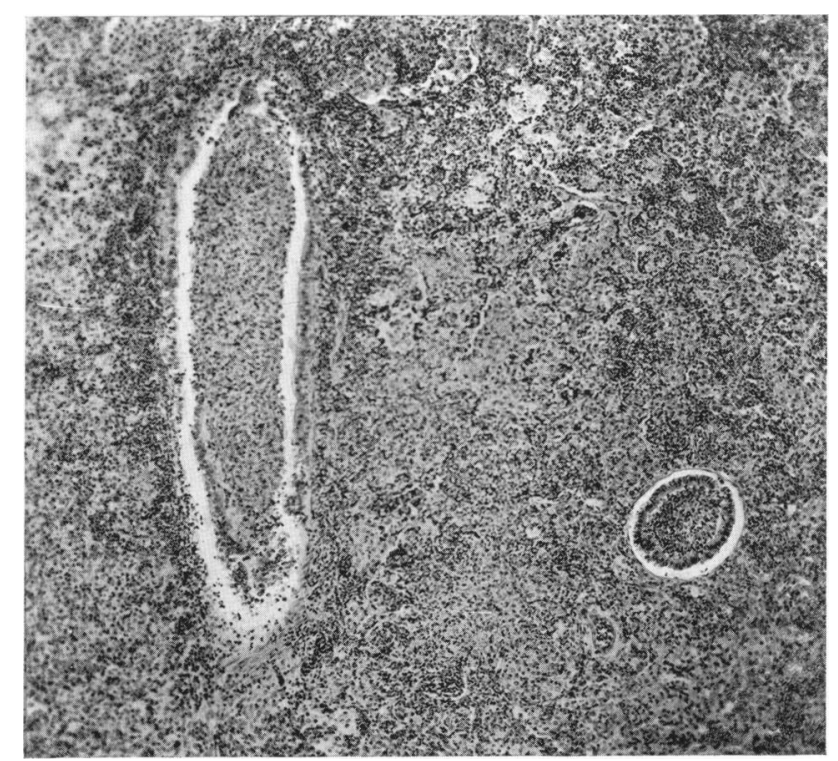

Fig. 4.-Lung of infant twelve days old. Pneumococcal alveolar pneumonia : uniform complete alveolar consolidation; bronchial walls undamaged. H. and E. $\times 65$.

is alveolar rather than bronchial, and avoids reference to the gross distribution and extent of consolidation. It is preferable to 'lobular,' as common usage has made that term almost synonymous with 'bronchopneumonia.' It has the further advantage that it indicates the essential identity of this type of pneumonia in the new-born with the better known and more typical forms of pneumococcal pneumonia in older children and adults.

2. Haematogenous infections of the lungs.-In a group of eighteen cases the inflammatory changes in the lungs were part of a generalized septic infection that originated elsewhere, and were due to blood-spread infection. The lung lesions in nine cases took the form of septic infarcts or pyaemic abscesses, accompanied by septic pleurisy with purulent or sero-fibrinous effusion. In three cases of haemolytic streptococcal infection the lungs contained focal areas of consolidation, unrelated to bronchi and having the scattered distribution of embolic lesions, but without suppuration. 
In six cases the lesion was a septic pleurisy followed by secondary invasion of the lungs by means of a septic lymphangitis, which sometimes went on to suppuration. The ages of the babies ranged from four to twenty-two days, all but one being under one week. The pleurisy took the form of a viscid purulent exudate, usually scanty, without fibrin. Involvement of the lungs was often not detectable at necropsy, but sometimes slight consolidation was suspected, and in one case small subpleural abscesses were visible. Purulent exudate was found microscopically in dilated lymph vessels, both those of the pleural plexus and those of the deep perivascular plexus throughout the lungs (fig. 5 and 6). In some cases inflammatory infiltration of the septa and perivascular

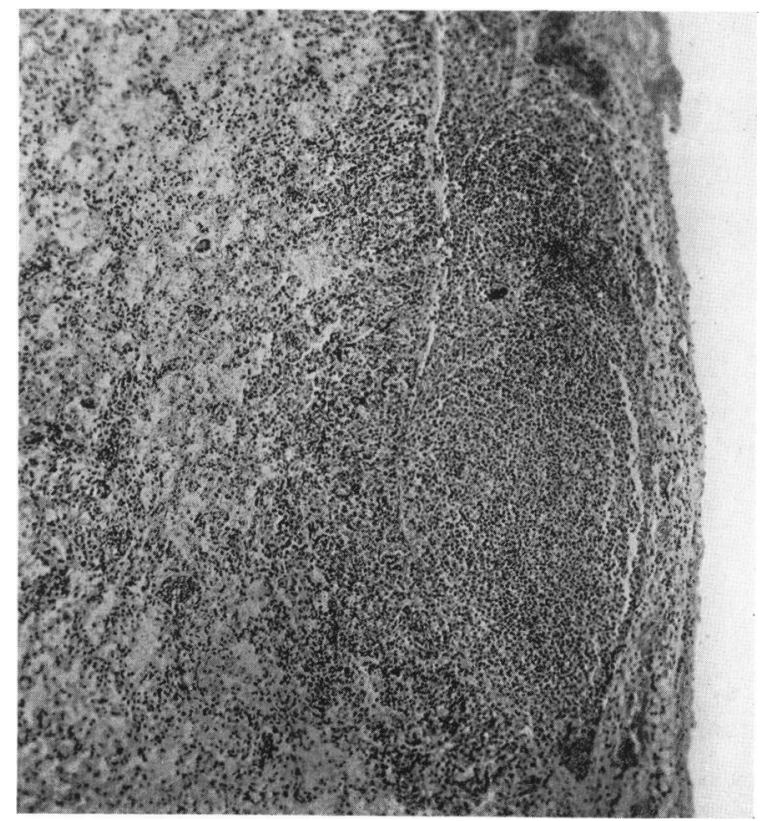

FIG. 5.-Lung of infant twenty-two days old. Septic lymphangitis following pleurisy : pleural lymph vessel distended with pus. H. and E. $\times 60$.

tissue and consolidation of adjoining alveoli were found. In several, abscesses had developed under the pleura or in interlobular septa. In all these cases the inflammatory changes in the lungs were entirely dependent on and secondary to the pleurisy. In the writer's experience this particular pathological process occurs only in very young infants. In older subjects there is little tendency for an infection of the pleura to invade the lung along the lymph vessels; this is prevented by valves which are situated at the junction of the pleural and septal lymphatics and open towards the pleura (Miller, 1919 and 1936). The fact that lymph-borne infection can pass so much more readily inward from pleura to lung in the new-born suggests that the development of these valves is incomplete until a little time after birth. Miller was able to produce some evidence to show that this is the case. 
In the whole group of haematogenous infections, six of the eighteen babies were premature. The ages ranged from four to twenty-eight days, eight being under a week old. Pleurisy with lymphangitis was commoner in the younger children, pyaemia or septic infarction after the first week. The primary focus of infection was established in ten cases in which infection was received after birth : umbilical sepsis in four, septic dermatitis in five, and otitis media in one. In one case the history strongly suggested intra-uterine transplacental infection. The mother had haemolytic streptococcal septicaemia before parturition; the baby died on the fourth day with haemolytic streptococcal septicaemia and pleurisy. This was the only case in the whole series in which any really suggestive evidence of transplacental infection was found. In the

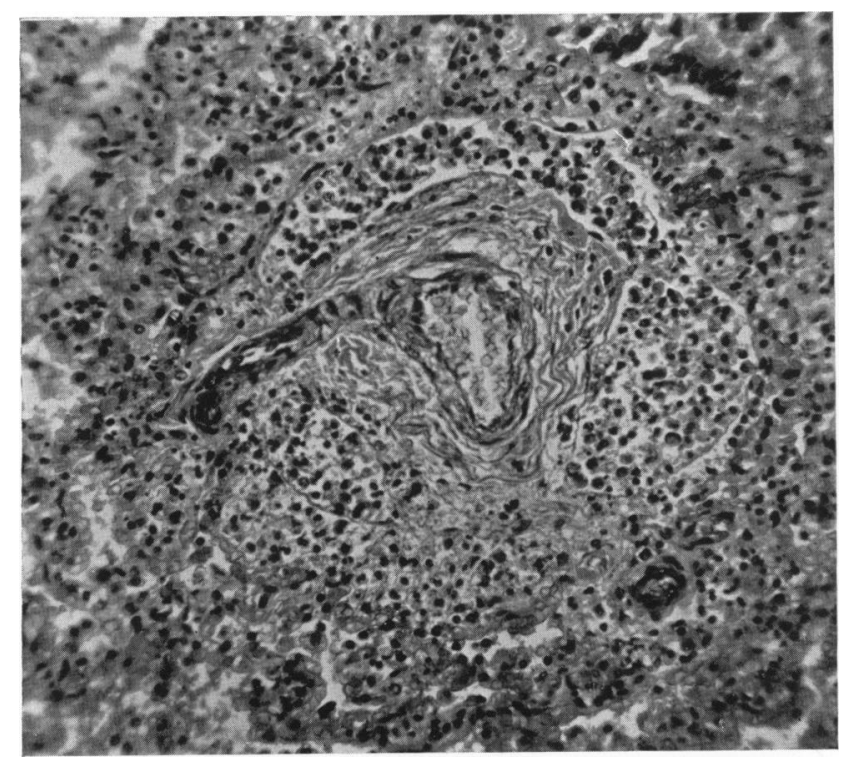

FIG. 6.-Lung of infant four days old. Septic lymphangitis following pleurisy : deep perivascular lymph vessels distended with pus. H. and E. $\times 180$.

remaining cases the source of infection and its primary site were obscure. Associated metastatic lesions in other parts of the body were found as follows : meningitis, five cases; abscesses in kidneys, two cases ; endocarditis and myocardial abscess, each one case.

Bacteriological examinations were made in all eighteen cases and in each resulted in the isolation of a single type of organism in pure culture : streptococcus haemolyticus in five ; streptococcus viridans in one ; staphylococcus aureus in six ; coliform bacilli in six. Blood cultures were made in eleven cases and in nine produced growths of the same organisms as were obtained from the lungs, but in two were spoiled by post-mortem contaminants. 


\section{Summary of the bacteriological study}

Bacteriological examinations were carried out in 150 cases in which inflammatory changes were found in the lungs. Positive results that were regarded as significant were obtained in 106 cases. The frequency of occurrence of the various organisms and their relation to the patient's age at death and to the pathological type of pneumonia are summarized in tables 1 and 2 . The types of bacteria that were frequently found included several species that commonly cause pneumonia in older people (haemolytic streptococci, pneumococci, b. influenzae). These were associated principally with those types of pneumonia that result from postnatal infection (bronchopneumonia and allied types, and-in the case of streptococcus haemolyticus-septicaemic infections), and occurred more often in the later part of the neonatal period than in the earlier

TABLE 1

BACTERIOLOGY IN RELATION TO AGE AT DEATH

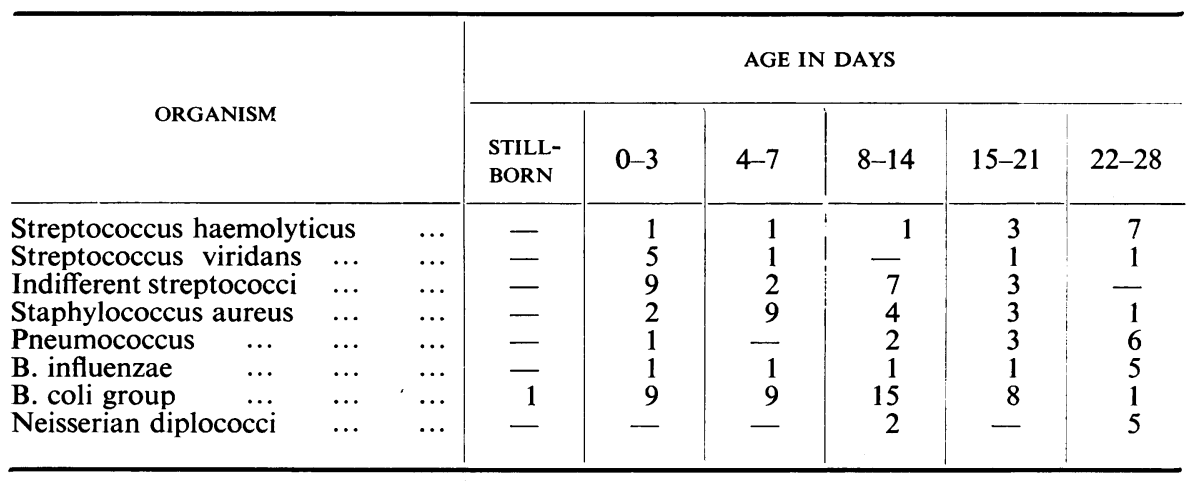

TABLE 2

BACTERIOLOGY IN RELATION TO PATHOLOGICAL TYPE OF PNEUMONIA

\begin{tabular}{|c|c|c|c|c|c|c|c|c|c|}
\hline \multirow[b]{2}{*}{ TYPE OF PNEUMONIA } & & \multicolumn{8}{|c|}{ ORGANISM } \\
\hline & & 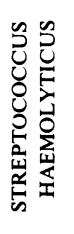 & 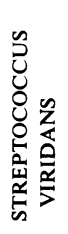 & 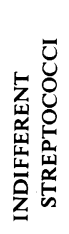 & 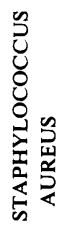 & 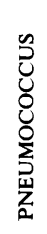 & 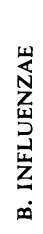 & 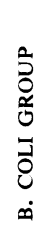 & 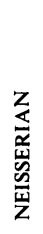 \\
\hline Prenatal aspiration & $\ldots$ & - & 3 & 5 & 1 & - & 1 & 6 & - \\
\hline Atelectasis $\quad \ldots$ & $\cdots$ & 2 & 2 & 3 & - & - & - & 4 & - \\
\hline Haemorrhage $\quad \ldots$ & $\ldots$ & - & - & 3 & 1 & - & - & 2 & - \\
\hline Postnatal aspiration $\quad \ldots$ & $\ldots$ & - & - & - & - & - & - & 5 & 1 \\
\hline $\begin{array}{l}\text { Bronchopneumonia and } \\
\text { bronchitis }\end{array}$ & & 6 & 2 & 10 & 1 & 6 & 8 & 19 & 6 \\
\hline Staphylococcal pneumonia & $\cdots$ & - & - & - & 10 & - & - & 1 & - \\
\hline Alveolar pneumonia $\quad \ldots$ & $\ldots$ & - & - & - & - & 6 & - & - & - \\
\hline Haematogenous lesions & $\ldots$ & 5 & 1 & - & 6 & - & - & 6 & 一 \\
\hline
\end{tabular}


days. There were also several species that are less often a cause of pneumonia in older subjects (streptococci of viridans and indifferent types and the $b$. coli group). These were the usual cause of the types of pneumonia that are peculiar to the neonatal period, and they occurred with great frequency in the earliest days of life. The b. coli group, however, caused all types of pneumonia (except those specifically associated with staphylococci and pneumococci) and were particularly common in typical bronchopneumonia. Staphylococcal infections were usually postnatal, but occurred early in the neonatal period. Some interesting considerations that arise from these facts are discussed below.

\section{Discussion}

From the point of view of prevention these cases in which infection is received after birth are of the first importance. Whether a case belongs to the respiratory or to the haematogenous group, infection received after birth is infection received from the child's environment and is therefore capable of being checked or controlled at the source. Of all the types of pulmonary infection studied during this investigation, those attributable to postnatal respiratory tract infection formed the largest group, and in the great majority of these cases pneumonia was the direct cause of death. It is undoubtedly in this group that the largest number of deaths from pneumonia could be prevented.

One of the most interesting facts revealed by the investigation of these cases of postnatal infection was the frequent appearance, as causative organisms, of types of bacteria that seldom appear in a similar rôle in older subjects. The most conspicuous example of this was the group of coliform bacilli. It must be explained that stringent precautions were taken to exclude the fallacy of post-mortem and terminal invasions of the body by intestinal bacteria, which undoubtedly takes place often and rapidly in new-born infants. No case was regarded as being due to infection with b. coli unless (a) films of lung juice and sections of pneumonic lung showed profuse phagocytosis of the bacilli by cells in the exudate (fig. 7 and 8), and (b) the distribution of the pneumonic areas in sections of the lungs corresponded to that of the bacilli. It was considered that the strict application of this rule excluded all reasonable possibility of mistaking post-mortem or terminal invaders of the tissues for genuine pathogens. In particular, the amount of phagocytosis found in many cases was so remarkable that it could not be doubted that the bacilli represented an antemortem infection. When any reasonable doubt existed the result was regarded as inconclusive and set aside.

Browne (1921 and 1922) considered that the frequency of b. coli in neonatal pneumonia was proof of the importance of infection before or during birth. But this investigation showed that $b$. coli infection occurred not only in cases in which prenatal infection was probable or possible, but even more often in older babies in whom infection before delivery was improbable or impossible and that it was most often associated with pneumonia of a type that is much more likely to be caused by air-borne or droplet infection than by aspiration. The most frequent appearances of organisms of the b. coli 


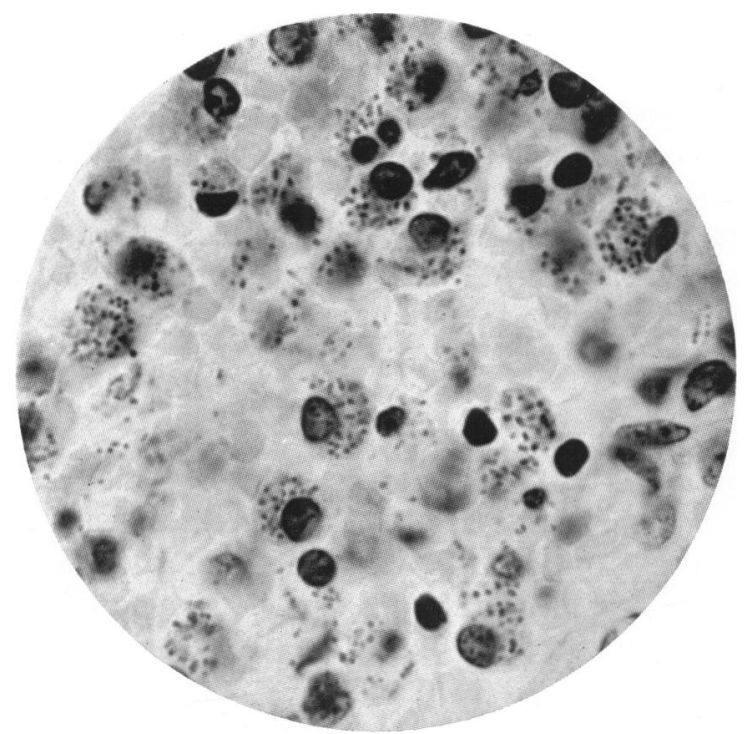

Fig. 7.-Lung of infant four days old. Case of b. coli bronchopneumonia : profuse phagocytosis of bacilli by cells in exudate. H. and E. $\times 900$.

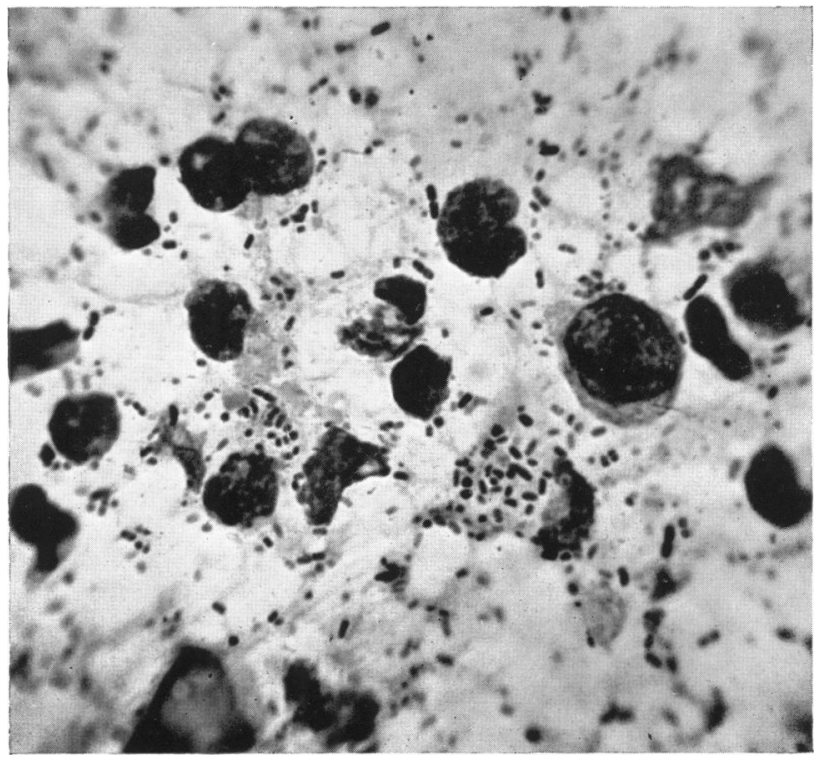

FIG. 8.-Film of exudate from lung. Case of $b$. coli bronchopneumonia : cells containing many ingested bacilli. Gram's stain. $\times 1100$. 
group were in cases of typical bronchopneumonia in babies more than a week old. They appeared also as a not infrequent cause of septicaemia in cases without evidence of prenatal aspiration. This matter is important because pneumonia due to coliform bacilli (other than the bacillus of Friedländer) seems to be peculiar to the neonatal period. In this series its prevalence ended at the end of the third week of life. The writer has made many bacteriological examinations in cases of pneumonia in infants and children and has never seen one caused by any member of the colon bacillus group after the first month of life. Yet during the first three weeks they are among the commonest of all bacteria associated with pneumonia. This is a remarkable fact and seems to indicate the existence of a special susceptibility in the new-born to infection by these organisms.

In the literature a considerable body of evidence suggests this special susceptibility, with reference not only to pneumonia but also to general sepsis and meningitis. Whereas septicaemia due to $b$. coli and related organisms is recognized to be rare in older persons, numerous authors have commented on its frequency or reported cases in the new-born (Ylppö, 1919; Cruickshank, 1930 ; Dunham, 1933 ; Park and Williams, 1934 ; Merritt and Paige, 1935 ; Butler, 1937). Meningitis due to these organisms has been frequently reported in the new-born (Ylppö, 1919 ; Cook and Bell, 1922 ; Neal, 1924 ; Cruickshank, 1930 ; Park and Williams, 1934; Craig, 1936; Mulhern and Seelye, 1936; Crockford, 1938), though similar cases in older subjects are very rare. There is therefore a good case for the contention that new-born babies are peculiarly susceptible to infection with these organisms.

Various suggestions have been offered to explain the frequency of $b$. coli infection in the new-born : undue absorption of bacteria from the bowel (Cook and Bell, 1922 ; Ylppö, 1919) ; an absence of 'normal' agglutinins for these organisms in the blood (Cook and Bell, 1922 ; Park and Williams, 1934; Zinsser and Bayne-Jones, 1934); and inadequate inflammatory reaction to bacterial invasion, manifested by a lack of polymorphonuclear leucocytes in the exudate (Ylppö, 1919 ; Browne, 1921 and 1922 ; Gordon and Lederer, 1928 ; Müller and Bayer, 1934).

The first of these suggested explanations may meet some cases of septicaemia of obscure origin, but hardly suffices for pneumonia of the primary type. The second is of doubtful accuracy, and, in view of the results of immunological studies of the b. coli group (Mackie, quoted by Muir and Ritchie, 1932), it may be doubted whether, even in older subjects, humoral antibodies provide any substantial protection against these organisms. The third is entirely at variance with the writer's experience. It is possible that the explanation of the special susceptibility of the new-born may be found to lie in the direction of local tissue immunity. It may be suggested that the mucous membranes of the alimentary and respiratory tracts acquire a local immunity against organisms of the b. coli group through constant or repeated contact with them, and so resist invasion by them, except perhaps in small and harmless numbers ; and that this immunity is absent, or incomplete, at birth, and is gradually acquired during the first weeks of life. There would thus be a period immediately following birth, when these organisms first enter the body of the child and for a time thereafter, when there is a greater risk of virulent invasion of the blood and 
tissues. Applied to the intestinal mucous membrane, this may explain some of the cases of b. coli septicaemia for which no obvious source is found, but no doubt in the case of the intestine, where colon bacilli must inevitably, speedily and numerously arrive soon after birth, any early tendency to virulent invasion must soon be overcome. In the case of the respiratory tract, where they are not regularly present, though their appearance is by no means rare (Gundel and Schwartz, 1931-32), the tendency to virulent invasion is probably greater and more prolonged. Moreover, it may well be greater in the case of premature infants.

Nor is it only with regard to colon bacillus infections that a special susceptibility in the new-born is manifested. Staphylococcal pneumonia is another interesting example. It is not confined to the neonatal period, or even to childhood, but is rare in older persons, whereas it is comparatively common in the new-born. Moreover, in most cases in adults the invasion of the lungs by staphylococci is preceded by infection of some other kind, most often influenza, as if the staphylococci are ordinarily incapable of virulent invasion of a healthy respiratory tract and become dangerous only when the mucous membrane has been rendered vulnerable by a preceding infection. In the very young the staphylococcal infection is in most cases primary and pure ; the staphylococci can exert their full pathogenic action on the respiratory tract without the help of any antecedent or coincident infection of another kind.

The results of this investigation of postnatal infection point clearly to one conclusion of great importance : the vital need for the most scrupulous attention in every detail to hygienic measures directed towards guarding the new-born against exposure to infection, especially infection of the respiratory tract, and the necessity that those who have charge of them should clearly appreciate the extent of the risk against which they must be protected. All are agreed that new-born babies must not be exposed to infection by contact with persons who are harbouring known pathogenic bacteria, but it is not so fully understood that organisms that are common and harmless commensals in the mouth, nose or pharynx of older people are potentially dangerous pathogens to the new-born.

It follows that young infants should be handled and fondled as little as may be by older persons; that crowded conditions, in which the bacterial content of the atmosphere is bound to be high, are dangerous to them ; and that attention to the hygiene of the baby's mouth and nose, and of the mother's breast when she suckles her child cannot be too careful. This has a bearing on the care of new-born babies in their own homes. It applies with equal or even greater cogency to the practice of infant hygiene in maternity hospitals, where, if conditions fall short of the best attainable, the babies may be exposed to risks that are not always fully realized. It is clearly undesirable that they should spend more time than that needed for suckling in the adult wards, especially if these contain a number of patients, when an atmosphere too rich in bacteria to be suitable for young infants can hardly be avoided. It is also inadvisable that the nurses in charge of the adult wards should at the same time have the care of the babies, because a satisfactory regime of infant hygiene 
requires the constant supervision of one who has special experience, and because if nurses have to divide their attention between mothers and babies, there are obvious risks of lapses in technique which may open the way to dangerous infection.

These conclusions received interesting confirmation from a comparison of the records, as regards neonatal pneumonia, of two hospitals. Hospital A was old and overcrowded and has now been superseded by a modern hospital. The babies ordinarily shared the adult wards with their mothers and were cared for by the nursing staff of their wards, upon whom devolved at the same time the care of the mothers. The medical and nursing staff thus worked under the disadvantage of conditions that made a satisfactory regime of infant hygiene impossible. Hospital B is modern, well situated, not overcrowded. The babies have their own nursery and go to their mothers' wards only for suckling. There is ample provision for the isolation of any child who develops an infection, and a hygienic regime of a high standard is maintained. The conditions under which the babies lived in the two institutions were thus suficiently different in certain essential respects to make a comparison of the results obtained both interesting and instructive (table 3 ).

TABLE 3.

NEONATAL PNEUMONIA IN TWO HOSPITALS (A AND B)

\begin{tabular}{|c|c|c|c|c|c|c|c|}
\hline & & \multicolumn{2}{|c|}{$\begin{array}{l}\text { NUMBER OF } \\
\text { CASES }\end{array}$} & \multicolumn{2}{|c|}{$\begin{array}{l}\text { PER CENT. OF } \\
\text { ALL PNEUMONIA }\end{array}$} & \multicolumn{2}{|c|}{$\begin{array}{l}\text { PER CENT. OF } \\
\text { ALL NECROPSIES }\end{array}$} \\
\hline & & $\mathbf{A}$ & B & $\mathbf{A}$ & B & A & B \\
\hline $\begin{array}{l}\text { Total necropsies } \ldots \\
\text { Total pneumonia } \ldots \\
\text { Pneumonia in first } 3 \text { days } \\
\text { Pneumonia in first week .... } \\
\text { Pneumonia after first } 3 \text { days } \\
\text { Pneumonia after first week } \\
\text { Postnatal airborne infection }\end{array}$ & $\begin{array}{l}\cdots \\
\cdots \\
\cdots \\
\cdots \\
\cdots \\
\cdots\end{array}$ & $\begin{array}{r}358 \\
117 \\
42 \\
68 \\
75 \\
49 \\
51\end{array}$ & $\begin{array}{r}118 \\
24 \\
18 \\
23 \\
6 \\
1 \\
2\end{array}$ & $\begin{array}{l}\overline{-} \\
36 \\
58 \\
64 \\
42 \\
43 \cdot 5\end{array}$ & $\begin{array}{l}\overline{-} \\
\overline{75} \\
96 \\
25 \\
4 \\
8 \cdot 3\end{array}$ & $\begin{array}{l}32 \cdot 7 \\
11 \cdot 7 \\
19 \\
21 \\
13 \cdot 7 \\
14 \cdot 2\end{array}$ & $\begin{array}{c}\overline{20} \\
15 \cdot 4 \\
19 \cdot 5 \\
5 \\
0 \cdot 8 \\
1 \cdot 7\end{array}$ \\
\hline
\end{tabular}

The percentage of necropsies in which pneumonia was found was considerably higher in Hospital A than in Hospital B, the figures being 32.7 and 20 per cent. respectively. The contrast is more striking and much more significant when a comparison is made of the pneumonia cases in the two hospitals in respect of age incidence and pathological type. In hospital A many cases occurred after the third day and even after the end of the first week, and cases continued to occur up to the end of the month. In Hospital B few cases occurred after the third day and only one child died with pneumonia after the first week. In Hospital A cases of the types caused by postnatal air-borne or droplet infection (i.e. environmental infection of the respiratory tract) were common (43.5 per cent. of all pneumonia cases and 14 per cent. of all necropsies). In Hospital B the incidence of environmental infection was low-two cases. representing 8 per cent. of all pneumonia and 1.7 per cent. of all necropsies. 
It is thus shown that in Hospital A primary pneumonia due to postnatal respiratory tract infection accounted for little less than half of all the pneumonia in the new-born and was responsible for a substantial proportion of the whole death rate. The bacteriological findings showed that the virulent respiratory tract pathogens (streptococcus haemolyticus, pneumococcus, b. influenzae) were of less frequent occurrence than other common organisms (staphylococci and the coliform bacilli) which occur as commensals in the mouth and throat, or otherwise about the persons of many healthy people, and might be expected to be more numerously present in the case of adult patients being nursed in bed, and of nurses in attendance on them, and to be present in the atmosphere of their wards. In Hospital B nearly all the pneumonia that occurred among the babies was either associated with birth asphyxia or secondary to lung injury caused by stress of birth or to massive pulmonary haemorrhage ; and in most of these cases the bacteriological results were inconclusive or negative. The two cases in which pneumonia was attributable to postnatal respiratory tract infection were both due to $b$. influenzae. There was no case of primary pneumonia due to staphylococci or b. coli. But for the two cases mentioned, this hospital was free from fatal postnatal primary respiratory tract infections among the babies for the entire period of four years covered by the investigation.

It is not to be believed that this difference in the incidence of postnatal infection is unconnected with the different conditions under which the babies lived in the two hospitals. The facts revealed by this comparison afford strong support for the argument here presented, and much encouragement may be had from them. For they show that pneumonia in the new-born due to postnatal infection is preventable and can be almost completely eliminated by scrupulous attention to hygienic principles that are already known.

In conclusion, therefore, it may be stated that the prevention of neonatal pneumonia of the types that develop after the first two or three days of life is entirely a problem of hygiene and nursing care. New-born babies must be protected, not only from infection with recognized pathogens, but also from conditions that occasion a too heavy invasion of the respiratory tract by common commensals, of which the most dangerous are staphylococcus aureus and organisms of the colon bacillus group. To accomplish this demands a hygienic regime of a high standard. The maintenance of the necessary standard is particularly important in institutions, where otherwise conditions may favour the spread of infection among the many susceptible infants. It can be asserted quite definitely that this type of pneumonia is preventable and could be almost completely abolished if a satisfactory system of neonatal hygiene were universally practised.

\section{Summary}

An account is given of the pathological characters and bacteriology of the types of neonatal pneumonia that are attributable to postnatal infection.

The largest group was formed by cases having the characters of typical bronchopneumonia. Cases with special characters associated with staphylococcal and pneumococcal infection are described. 
Some peculiarities of haematogenous infections of the lungs in the new-born are discussed.

A summary of the bacteriological study is given. The importance of organisms of the colon bacillus group in neonatal infections is discussed.

A comparison of the incidence of neonatal pneumonia in two hospitals is given.

The conclusion is reached that pneumonia due to environmental infection can be prevented by strict attention to neonatal hygiene.

It is a pleasure to express gratitude to Prof. Charles McNeil, whose unflagging interest in the work was a source of constant encouragement. Thanks are due to the members of the visiting staffs of the Royal Maternity Hospital, the Elsie Inglis Memorial Maternity Hospital and the Royal Hospital for Sick Children, Edinburgh, for the use of clinical records ; to Dr. W. S. Craig and Dr. J. L. Henderson, for help in performing some of the necropsies and in the analysis of clinical records ; and to Mr. Edward Gorton, for technical assistance throughout the investigation.

The expenses of the investigation were met by a grant from the Medical Research Council.

\section{REFERENCES}

Browne, F. J. (1921). Edinb. met. J., 27, 153.

- (1922). Brit. med. J., 1, 469.

- (1922). Ibid., 2, 590.

Butler, H. M. (1937). Blood Cultures and their Significance, London.

Chase, W. H. (1935). Canad. med. Ass. J., 32, 2.

Cook, J. V., and Bell, H. H. (1922). Amer. J. Dis. Child., 24, 387.

Craig, W. S. (1936). Arch. Dis. Childh., 11, 171.

Crockford, A. L. (1938). Brit. med. J., 1, 1101.

Cruickshank, J. N. (1930). Medical Research Council Special Reports, No. 145.

Dunham, E. C. (1933). Amer. J. Dis. Child., 45, 229.

Gordon, A. S., and Lederer, M. (1928). Ibid., 36, 764.

Gundel, M., and Schwartz, F. K. (1931-32). Z. Hyg. Infektkr., 113, 411.

Holt, L. E., and McIntosh, R. (1933). Holt's Diseases of Infancy and Childhood, 10th edition, 438.

Johnson, W. C., and Meyer, J. R. (1925). Amer. J. Obstet. Gynec., 9, 151.

Macgregor, A. R. (1936). Arch. Dis. Childh., 11, 195.

McNeil, C., Macgregor, A. R., and Alexander, W. A. (1929). Ibid., 4, 12, 83, 111.

Merritt, K. K., and Paige, B. H. (1935). Amer. J. Dis. Child. 50, 693.

Miller, W. S. (1919). Amer. Rev. Tuberc., 3, 193.

- (1936). The Lung, Springfield, Illinois.

Muir, R., and Ritchie, J. (1932). Manual of Bacteriology, 9th edition, London, 428.

Mulhern, M. E., and Seelye, W. B. (1936). J. Lab. clin. Med., 21, 793.

Müller, C., and Bayer, W. (1934). Arch. Gynaek., 157, 372.

Neal, J. B. (1924). J. Amer. med. Ass., 82, 1429.

Park, W. H., and Williams, A.W. (1934). Pathogenic Microorganisms, 10th edition, London, 432.

Ylppö, A. (1919). Z. Kinderheilk, 20, 371.

Zinsser, H., and Bayne-Jones, S. (1934). Textbook of Bacteriology, 7th edition, New York and London. 